\title{
Prevalence of cardiovascular risk factors among adults without obvious cardiovascular disease in a rural community in Ekiti State, Southwest Nigeria
}

\author{
Olarinde J Ogunmola ${ }^{1 *}$, Adeleke O Olaifa ${ }^{2}$, Olutoyin O Oladapo ${ }^{3}$ and Oluwole A Babatunde ${ }^{4}$
}

\begin{abstract}
Background: Cardiovascular disease worldwide is largely driven by modifiable risk factors. This study sought to identify and determine the prevalence of traditional cardiovascular risk factors according to sex in inhabitants of a rural community in a developing country.

Methods: This cross-sectional study included participants aged $\geq 40$ years in the rural community of Aaye Ekiti, Ekiti State, Southwest Nigeria. All participants who met the inclusion criteria were drawn from the 161 households in the community. Data on the following were collected: arterial hypertension, diabetes mellitus, obesity, dyslipidaemia, smoking, physical activity, alcohol consumption, and sociodemographic parameters. These were analysed with SPSS version 16.0 software.

Results: The 104 participants (33 male, 71 female) had a mean age ( \pm standard deviation) of $66.77 \pm 12.06$ years (range, 40-88 years). The majority of the participants (56.7\%) were aged 60-79 years. Hypertension was present in $66.4 \%$, diabetes mellitus in $4.8 \%$, abdominal obesity in $38.46 \%$, smoking in $2.9 \%$, physical inactivity in $29.8 \%$, and high alcohol consumption in 1\%. Dyslipidaemia, as represented by low HDL-C, occurred in $30 \%$. There were borderline high levels of TC in 4.5\%, LDL-C in 1.1\%, and TG in 12.5\%, but no subject had a high level. Abdominal obesity, alcohol consumption and smoking were statistically significantly associated with sex.

Conclusion: In this study, traditional cardiovascular risk factors, apart from hypertension, obesity, physical inactivity and low HDL-C had a low prevalence in the rural Nigerian community. However, the high prevalence of hypertension in this poor community suggests a high risk of a future cardiovascular event.
\end{abstract}

Keywords: Hypertension, Cardiovascular disease, Risk factors, Rural communities, Nigeria

\section{Background}

Cardiovascular disease (CVD) is the leading cause of death in adults worldwide [1]. In developing countries, the proportion of worldwide deaths associated with CVD is projected to rise from $28.9 \%$ in 1990 to $36.3 \%$ by the year 2020 [2]. CVD now causes most deaths in all developing regions, and is the leading cause of death in those older than 45 years in sub-Saharan Africa [3].

CVD worldwide is largely driven by modifiable risk factors. These risk factors include smoking, lack of physical activity, low fruit and vegetable intake, high fat and

\footnotetext{
* Correspondence: joogunmola@yahoo.com

'Department of Internal Medicine, Cardiac Centre, Federal Medical Centre, Ido-Ekiti, Ekiti State, Nigeria

Full list of author information is available at the end of the article
}

salt intake, hypertension, abdominal obesity, dyslipidaemia, and excess alcohol intake [3]. The upward trend in CVD in sub-Saharan Africa is likely as a result of the increasing prevalence of some of these modifiable risk factors [3].

The continuing enormous burden of CVD in developed countries, the concerning trends in cardiovascular risk profiles of adolescents and adults, and the emerging increases in CVD in developing countries underscore the crucial need to redouble treatment and prevention efforts [4]. This is particularly important in Nigeria (and by extension, Africa), where the health care expenditure per capita is 23 dollars (4.6\% of total Gross Domestic Product) [5]. Therefore, this study sought to identify and determine the prevalence of traditional (conventional)

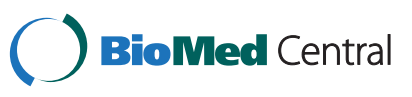


cardiovascular risk factors according to sex and sociodemographic factors, in residents of a typical Nigerian rural community.

To the best of the authors' knowledge, no known study of this nature has been conducted in Ekiti State, and no recent study has been conducted in Southwest Nigeria to comprehensively assess CVD risk factors. We hypothesised that traditional cardiovascular risk factors were of low frequency in rural dwellers of Ekiti in Ekiti State, Nigeria. This study was conducted to provide epidemiological information on conventional cardiovascular risk factors among rural dwellers, and therefore a useful reference for preventive strategies, policy formulation and further studies.

\section{Methods}

\section{Study population}

This study was a descriptive, cross-sectional survey conducted in Aaye Ekiti, a typical rural community in the Ido/Osi Local Government Area of Ekiti State, Southwest Nigeria. It is situated about $30 \mathrm{~km}$ from Ado-Ekiti, the state capital. The major occupation is farming, mainly cultivation of root crops. The community has an estimated population of 1,610 , and is divided into four quarters, namely Onala (51 houses), Oke-Ode (28 houses), Odo-ode (22 houses), and Temidire (60 houses), with a total number of 161 houses, which were visited during the enrolment process. Eligible households were defined as one having participants that met the inclusion criteria. A total of 120 participants were enrolled.

The inclusion criteria were: age $\geq 40$ years; no apparent cardiovascular disease; had lived for at least 3 years in the community; and provided consent to participate in the study. The exclusion criteria were: pregnancy and incapacity to give informed consent.

The community consisted mainly of children and elderly inhabitants, but few young adults, the majority of whom had migrated to the cities for white-collar jobs. Those in the community who met the inclusion criteria were encouraged to participate by community leaders, chiefs and announcements in strategic places, e.g., the church, meetings and community gatherings. The only comprehensive health centre available in the community was used to evaluate all subjects recruited for this study.

\section{Ethical consideration}

The project was approved by the committee on ethics of the Federal Medical Centre Ido-Ekiti, Ekiti State. Permission to use the health centre was obtained from the officer in charge. Individual participant written consent was obtained after a thorough explanation was given and understanding was established. Confidentiality was assured to all participants and data used for this study were stripped of personally identifiable information. Treatment (both preventive and curative) was given to all those who were identified as requiring it, and some were referred to appropriate health institutions for further treatment and follow-up.

The following definitions were adopted for this study. Hypertension: persistently elevated blood pressure (BP) $\geq 140 / 90 \mathrm{mmHg}$, based on at least two readings on separate occasions after the initial screening [6-9]. The choice of $140 / 90 \mathrm{mmHg}$ as a cut-off point is based on the Seventh Report of the Joint National Committee on prevention, detection, evaluation and treatment of high blood pressure (JNC 7) criteria [7]. Diabetes mellitus and impaired fasting blood glucose: diagnosed according to the World Health Organization diagnostic criteria [10]. Rural community: an area where people work or live on a farm or the number of residents is less than 2000 [11]. Dyslipidaemia: National Cholesterol Education Programme Adult Treatment Panel III (NCEP ATP III) cut-off points were used to identify participants with desirable, borderline high and high levels of lipoprotein risk factors [12] — total cholesterol (TC): $\leq 4.9 \mathrm{mmmol} / \mathrm{L}$, 5-5.9 $\mathrm{mmol} / \mathrm{L}$ and $\geq 6.0 \mathrm{mmol} / \mathrm{L}$, respectively; low density lipoprotein cholesterol (LDL-C): $<3.24 \mathrm{mmol} / \mathrm{L}$, $3.25-3.98 \mathrm{mmol} / \mathrm{L}$, and $\geq 4.0 \mathrm{mmol} / \mathrm{L}$, respectively; triglyceride (TG): $<1.70 \mathrm{mmol} / \mathrm{L}, 1.70-2.25 \mathrm{mmol} / \mathrm{L}$, and $\geq 2.26 \mathrm{mmol} / \mathrm{L}$, respectively; high density lipoprotein cholesterol (HDL-C) cut-off points used to identify participants with protective, borderline, and low levels were: $\geq 1.5 \mathrm{mmol} / \mathrm{L}, 1.0-1.4 \mathrm{mmol} / \mathrm{L}$, and $\leq 0.9 \mathrm{mmol} / \mathrm{L}$, respectively. Classification of body mass index (BMI) $[13,14]$ : normal $=18.5-24.9 \mathrm{~kg} / \mathrm{m}^{2} ;$ overweight $=25.0-$ $29.9 \mathrm{~kg} / \mathrm{m}^{2}$; obese $=\geq 30 \mathrm{~kg} / \mathrm{m}^{2}$. Abdominal obesity: waist circumference $>102 \mathrm{~cm}$ in males or $>88 \mathrm{~cm}$ in females [14]. Alcohol intake: calculated as the percentage of alcohol by volume multiplied by the volume divided by 1000 ; low-risk alcohol consumption was defined as a maximum of 3 units per day in females, and a maximum of 4 units per day in males, with at least 2 days per week free of alcohol consumption [15]; higher consumption was considered high risk. Smoking: considered present if smoking was reported up to the day of the interview. Level of physical activity: determined using the modified Hipny Physical Activity Questionnaire (based on the Health Insurance Plan (HIP) of New York questionnaire) [16]; insufficient physical activity was considered if occupation-related activity was less than 15 units on the validated HIP scale, or leisure-related physical activity was less than 4 units on the scale.

\section{Data collection}

All health professionals involved in this study received training in the protocols and in the measurement of all variables involved in this study, to ensure uniformity and minimize errors. A pre-test was undertaken and necessary 
modification adopted, before the main data collection was performed. Each participant was comfortably seated and assessed for all the listed conventional cardiovascular risk factors as well as taken through a well-structured questionnaire that consisted of sociodemographic characteristics. Height $(\mathrm{m})$ and weight $(\mathrm{kg})$ were measured by standardized techniques and equipment [17]. The reference point used to measure waist circumference with a non-stretchable tape was the highest point of the iliac crest. The narrowest region (visible waist) of the abdomen was used when this region did not coincide with the highest point of the iliac crest [18].

Socioeconomic status was assessed using a general model $[19,20]$ as a convenient index for classification into lower class, middle class and upper class, since the majority of the population were peasant farmers. BP was measured with a mercury sphygmomanometer at least twice in each participant with at least 5 min of rest in between, with the subject seated in a chair and relaxed, the back supported, and the arm at heart level. During the initial screening, BP both arms was measured and the arm with higher BP used subsequently. Tobacco, alcohol and caffeine were not allowed for at least $30 \mathrm{~min}$ before taking the measurements.

Fasting blood glucose and fasting lipid profile were determined using capillary blood obtained from a pin prick on finger Pulp using Cardio Check P.A Polymer Technology systems, Inc., a point of care analyser that is a reliable alternative to conventional laboratory devices. Accuracy of the equipment was $\pm 6 \%$ compared with standard laboratory equipment.

\section{Statistical analysis}

Data were entered into a statistical computer software package (SPSS version 16.0, SPSS Inc., Chicago, IL, USA). The Student $t$-test was used to determine means \pm standard deviation, and the Chi-square test was used for proportions. The Yates correction and Fisher extract test were used when the frequencies expected were lower than five in one or more cells, respectively. In those tests, a p-value of $<0.05$ was considered statistically significant.

\section{Results}

In this study, 104 participants were included out of 120 individuals that met the inclusion criteria. Fourteen lacking a fasting lipid profile and two with no random blood sugar results were excluded from further analysis. The final sample consisted of 33 males (31.7\%) and 71 females (68.3\%), with mean age $66.77 \pm 12.06$ years (range, $40-88$ years). The mean age for males was $69.45 \pm$ 10.36 years (range, $40-85$ years), and for females was $65.52 \pm 12.64$ years (range, $50-88$ years). The difference in the mean ages of males and females was not statistically significant $(\mathrm{t}=1.559, \mathrm{p}=0.122)$. None of the menopausal women received hormone replacement therapy. Table 1 presents the demographic characteristics: $26.0 \%$ were aged $40-59$ years, $56.7 \%$ were $60-79$ years, and $17.3 \%$ were $\geq 80$ years. Most participants were low-income earners and almost all belonged to the lower socioeconomic status. Over half of the participants had no formal education. Nearly all the participants were married and no males were widowed. There were no statistically significant differences in variables relating to sex except for marital status and occupation of participants.

Data of the traditional cardiovascular risk factors are presented in Table 2. BP measurements showed that $66.4 \%$ had systemic arterial hypertension. Systolic BP of all the participants ranged between 100 and $220 \mathrm{mmHg}$ (mean, $150.3 \pm 27.9 \mathrm{mmHg}$ ). In males, systolic BP ranged between 110 and $200 \mathrm{mmHg}$ (mean, $151.8 \pm 22.6 \mathrm{mmHg}$ ). In females, systolic BP ranged between 100 and $220 \mathrm{mmHg}$ (mean, $151.80 \pm 30.1 \mathrm{mmHg}$ ). The diastolic BP of all participants ranged between 60 and $120 \mathrm{mmHg}$ (mean, $87.5 \pm 13.7 \mathrm{mmHg}$ ). In males, diastolic $\mathrm{BP}$ ranged between 60 and $110 \mathrm{mmHg}$ (mean, $87.9 \pm 11.6 \mathrm{mmHg}$ ). In females, diastolic BP ranged between 60 and $120 \mathrm{mmHg}$ (mean, $87.3 \pm 14.7 \mathrm{mmHg}$ ). There were no significant differences between the sexes.

Blood glucose values of all participants ranged between 3.4 and $13.6 \mathrm{mmol} / \mathrm{L}$ (mean, $4.6 \pm 1.5 \mathrm{mmol} / \mathrm{L}$ ). In males, blood sugar ranged between 3.4 and $5.6 \mathrm{mmol} / \mathrm{L}$ (mean, $4.3 \pm 0.5 \mathrm{mmol} / \mathrm{L}$ ), and in females blood glucose ranged between 3.4 and $13.6 \mathrm{mmol} / \mathrm{L}$ (mean, $4.8 \pm$ $1.7 \mathrm{mmol} / \mathrm{L}$ ). In total, five subjects $(4.8 \%)$ were diabetic, and all were female (Table 2).

BMI ranged between 15.4 and $44.8 \mathrm{~kg} / \mathrm{m}^{2}$ (mean, $25.0 \pm 5.4 \mathrm{~kg} / \mathrm{m}^{2}$ ). In males, BMI ranged between 17.0 and $35.0 \mathrm{~kg} / \mathrm{m}^{2}$ (mean, $24.3 \pm 4.3 \mathrm{~kg} / \mathrm{m}^{2}$ ), and in females, BMI ranged between 15.3 and $44.8 \mathrm{~kg} / \mathrm{m}^{2}$ (mean, 25.4 \pm $5.8 \mathrm{~kg} / \mathrm{m}^{2}$ ). In total, $14.4 \%$ were obese, and $29.8 \%$ were overweight. There were no significant differences between the sexes.

The proportion of current smokers as shown in Table 2 was low. The proportion of participants consuming alcohol was $30.8 \%$, with only one subject at high risk of alcohol-related diseases. The level of physical activity showed that most of the population were physically active. There was also low proportion of male participants with abdominal obesity $(9.1 \%)$ in contrast to that observed for the females (52.1\%). There were statistically significant differences between the sexes in tobacco use, alcohol consumption and abdominal obesity (Table 2).

No significant dyslipidaemia was observed among the participants. There is no participant with high TC value, and $4.4 \%$ had borderline high TC. TC ranged from 2.45 to $5.38 \mathrm{mmol} / \mathrm{L}$ (mean, $3.66 \pm 0.64 \mathrm{mmol} / \mathrm{L}$ ). In males, TC ranged between 2.58 and $5.38 \mathrm{mmol} / \mathrm{L}$ (mean, $3.54 \pm$ $0.68 \mathrm{mmol} / \mathrm{L}$ ), and in females, TC ranged between 2.45 
Table 1 Sociodemographic characteristics of the participants by sex

\begin{tabular}{|c|c|c|c|c|c|}
\hline Variables & Male $(\mathrm{N}=33)$ & Female $(\mathrm{N}=71)$ & Total $(\mathrm{N}=104)$ & $x^{2}$ & $\mathrm{p}$-value \\
\hline \multicolumn{6}{|l|}{ Age group (years) } \\
\hline $40-59$ & $7(21.2)$ & $20(28.2)$ & $27(26.0)$ & 0.956 & 0.62 \\
\hline $60-79$ & $21(63.6)$ & $38(53.5)$ & $59(56.7)$ & & \\
\hline$\geq 80$ & $5(15.2)$ & $13(18.3)$ & $18(17.3)$ & & \\
\hline \multicolumn{6}{|l|}{ Socioeconomic status } \\
\hline Lower class & $30(90.9)$ & $66(93)$ & $96(92.3)$ & 2.194 & 0.33 \\
\hline Middle class & $2(6.1)$ & $5(7)$ & $7(6.7)$ & & \\
\hline Upper Class & $1(3)$ & $0(0)$ & $1(1)$ & & \\
\hline \multicolumn{6}{|c|}{ Highest educational level attained } \\
\hline No formal education & $14(42.4)$ & $43(60.6)$ & $57(54.8)$ & 5.262 & 0.15 \\
\hline Primary school & $7(21.2)$ & $16(22.5)$ & $23(22.1)$ & & \\
\hline Secondary school & $5(15.2)$ & $6(8.5)$ & $11(10.6)$ & & \\
\hline Post-secondary school & $7(21.2)$ & $6(8.5)$ & $13(12.5)$ & & \\
\hline \multicolumn{6}{|l|}{ Marital status } \\
\hline Single & $0(0.0)$ & $0(0.0)$ & $0(0.0)$ & 26.690 & 0.000 \\
\hline Married & $32(97.0)$ & $33(46.5)$ & 65 (62.5) & & \\
\hline Divorced & $1(3.0)$ & $1(1.4)$ & $2(1.9)$ & & \\
\hline Widowed & $0(0.0)$ & 37 (52.9) & 37 (35.9) & & \\
\hline \multicolumn{6}{|l|}{ Occupation } \\
\hline Farming & 27 (81.8) & $23(32.4)$ & $50(48.1)$ & 23.571 & 0.000 \\
\hline Trading & $1(3)$ & 27 (38.0) & $28(26.9)$ & & \\
\hline Others & $5(15.2)$ & $21(29.6)$ & $26(25.0)$ & & \\
\hline
\end{tabular}

and $5.32 \mathrm{mmol} / \mathrm{L}$ (mean, $3.73 \pm 0.66 \mathrm{mmol} / \mathrm{L}$ ). One female participant had borderline high LDL-C, and no high LDL$C$ level was recorded. LDL-C for all the participants ranged between 0.9 and $3.7 \mathrm{mmol} / \mathrm{L}$ (mean, $2.05 \pm$ $0.58 \mathrm{mmol} / \mathrm{L})$. In males, LDL-C ranged between 0.9 and $22.0 \mathrm{mmol} / \mathrm{L}$ (mean, $1.92 \pm 0.52 \mathrm{mmol} / \mathrm{L}$ ), and in females, LDL-C ranged between 0.95 and $3.7 \mathrm{mmol} / \mathrm{L}$ (mean, $2.12 \pm 0.60 \mathrm{mmol} / \mathrm{L})$. No participant recorded a high TG value, and less than $13 \%$ had a borderline high TG level (Table 3). Low HDL-C occurred in 30\% of males and females.

\section{Discussion and conclusions}

This study confirmed the hypothesis that most traditional risk factors for CVD are of low prevalence in rural dwellers of Ekiti in Ekiti State, Nigeria. Similar reports in other rural areas have been documented [21-24]. However, the prevalence of CVD risk factors has been shown to be on the increase both in Western and African countries, particularly in urban areas, while rural areas that have suffered from rural-urban migration are also becoming affected [25-27]. Communitybased studies in rural areas in developing countries are lacking because of a lack of funding.

The participants in this study were predominantly in the age group $60-79$ years $(56.7 \%)$ and there was a preponderance of females, possibly because many of the young adults, particularly males, had migrated to the cities for work, and more males than females were engaged in crude farming activities, which have long been recognized as a risk factor for earlier death in men [28-30]. The very old formed the lowest proportion $(17.3 \%)$ of the participants, which reflects the reduced life expectancy in low to middle income countries to which this community belonged [28]. Marital status, in which no males were widowed compared with $52.9 \%$ of females, may reflect the traditional practice in this community allowing men not only to marry more than one wife but to marry another wife in the event of the death of his wife. Furthermore, many young/middle-aged women were married to elderly men in the community. The majority of the participants belonged to the lower socioeconomic class, which was a reflection of their educational level $(54.8 \%$ had no formal education) and therefore their source of income was predominantly peasant farming and petty trading. Besides this form of self-employed low-income work, the community did not have access to industrial or government employment.

Of all the modifiable risk factors evaluated, hypertension was found to be the highest burden for the participants. This is similar to earlier reports from rural communities 
Table 2 Distribution of traditional cardiovascular risk factors according to sex

\begin{tabular}{|c|c|c|c|c|c|}
\hline Variables & $\begin{array}{c}\text { Male }(\mathrm{N}=33) \\
\mathrm{N}(\%)\end{array}$ & $\begin{array}{c}\text { Female }(N=71) \\
N(\%)\end{array}$ & $\begin{array}{c}\text { Total }(\mathrm{N}=104) \\
\mathrm{N}(\%)\end{array}$ & $x^{2}$ & $p$-value \\
\hline \multicolumn{6}{|l|}{ BP Category $(\mathrm{mmHg})$} \\
\hline$\geq 140 / 90$ & $13(39.4)$ & $31(28.1)$ & $44(42.3)$ & 2.095 & 0.55 \\
\hline$<140 / 90$ & $12(36.4)$ & $23(53.5)$ & $35(33.7)$ & & \\
\hline$\geq 140 /<90$ & $6(18.2)$ & $16(18.3)$ & $22(21.2)$ & & \\
\hline$<140 / \geq 90$ & $2(6.1)$ & $1(1.4)$ & $3(2.9)$ & & \\
\hline \multicolumn{6}{|l|}{ BMI $\left(\mathrm{kg} / \mathrm{m}^{2}\right)$} \\
\hline$<18.5$ & $2(6.1)$ & $4(5.6)$ & $6(5.8)$ & 3.070 & 0.38 \\
\hline $18.5-24.9$ & $17(51.5)$ & $35(49.3)$ & $52(50.0)$ & & \\
\hline $25-29.9$ & $12(36.4)$ & $19(26.8)$ & $31(29.8)$ & & \\
\hline$\geq 30$ & $2(6.0)$ & $13(18.3)$ & $15(14.4)$ & & \\
\hline \multicolumn{6}{|l|}{ Tobacco use } \\
\hline Non smoker & $19(57.6)$ & $69(97.2)$ & $88(84.6)$ & 32.15 & 0.000 \\
\hline Ex-smoker & $13(39.4)$ & $00(00.0)$ & $13(12.5)$ & & \\
\hline Current smoker & $1(3.0)$ & $2(2.8)$ & $3(2.9)$ & & \\
\hline \multicolumn{6}{|l|}{ Alcohol consumption } \\
\hline None & $9(27.3)$ & $63(88.7)$ & $72(69.2)$ & 40.247 & 0.000 \\
\hline Low risk & $23(69.6)$ & $8(11.3)$ & $31(29.8)$ & & \\
\hline High risk & $1(3.0)$ & $0(0.0)$ & $1(1.0)$ & & \\
\hline \multicolumn{6}{|l|}{ Blood sugar category } \\
\hline Diabetic & $0(0.0)$ & $5(7.0)$ & $5(4.8)$ & 6.723 & 0.08 \\
\hline Impaired fasting glucose & $1(3.0)$ & $3(4.2)$ & $4(3.8)$ & & \\
\hline Non diabetic & $30(90.9)$ & $63(88.7)$ & 93(89.4) & & \\
\hline No blood glucose result & $2(6.1)$ & $0(0.0)$ & $2(1.9)$ & & \\
\hline \multicolumn{6}{|l|}{ Waist circumference $(\mathrm{cm})$} \\
\hline$\leq 102$ (male), $\leq 88$ (female) & $3(90.9)$ & $34(47.9)$ & $64(61.5)$ & 17.617 & 0.000 \\
\hline$>102$ (male), >88 (female) & $3(9.1)$ & $37(52.1)$ & $40(38.5)$ & & \\
\hline \multicolumn{6}{|l|}{ Physical activity } \\
\hline Active & $25(75.8)$ & $48(67.6)$ & $73(70.2)$ & 0.716 & 0.60 \\
\hline Inactive & $8(24.2)$ & $23(32.4)$ & $31(29.8)$ & & \\
\hline
\end{tabular}

BP Blood pressure, $B M I$ Body mass index.

in Ghana and Nigeria [31,32]; however, a higher prevalence of hypertension was demonstrated in this study. Combined systolic and diastolic hypertension (42.3\%) was the commonest, followed by isolated systolic hypertension (ISH) (21.2\%), and last, pure diastolic hypertension (2.9\%). This may be explained by both the age structure of our population and the cut-off used to define hypertension. Over time, the cut-off value for hypertension has been lowered from $160 / 95 \mathrm{mmHg}$ to $140 / 90 \mathrm{mmHg}$, which is bound to identify more people as having hypertension. As observed in this study and others from similar rural and semi-urban communities, there was an age-related increase in the prevalence of hypertension [31-33]. About $74 \%$ of our participants were above 60 years of age and therefore could be classified as elderly people, hence the possibility of a greater burden of hypertension. Significant numbers of the women were also past the menopause, which could also contribute to the burden of hypertension [34].

The overall prevalence $(66.4 \%)$ of hypertension in this study was higher than in a study by Onwubere et al. [35] in Southeast Nigeria (46.4\%). However, this study considered a population of 40-88 years of age while the study of Onwubere et al. included a population with an age range of 40-70 years and in a different Nigerian tribe. These factors may contribute to the difference as genetic factors are very important in the development of hypertension. The same reasons are also applicable to the prevalence of hypertension in a rural community in the Northern part of Nigeria (15.2\%) reported by Okesina et al. [21]. The higher prevalence of ISH compared with pure diastolic hypertension in this study is expected, as the predominant age group was elderly and ISH is known to increase with age, unlike pure diastolic hypertension 
Table 3 Lipid panel distribution according to sex

\begin{tabular}{|c|c|c|c|c|c|}
\hline Variables & $\begin{array}{c}\text { Male }(\mathrm{N}=30) \\
\mathrm{N}(\%)\end{array}$ & $\begin{array}{c}\text { Female }(N=60) \\
N(\%)\end{array}$ & $\begin{array}{c}\text { Total }(\mathrm{N}=90) \\
\mathrm{N}(\%)\end{array}$ & $x^{2}$ & P-Value \\
\hline \multicolumn{6}{|l|}{$\mathrm{TC}(\mathrm{mmol} / \mathrm{L})$} \\
\hline$\leq 4.98$ & $29(96.7)$ & $57(95.0)$ & $86(95.5)$ & 63.375 & 0.167 \\
\hline $5.00-5.98$ & $1(3.3)$ & $3(5.0)$ & $4(4.5)$ & & \\
\hline$\geq 6.00$ & $0(0.0)$ & $0(0.0)$ & $0(0.0)$ & & \\
\hline \multicolumn{6}{|l|}{ LDL-C (mmol/L) } \\
\hline$<2.50$ & $27(90.0)$ & $42(70.0)$ & 69 (76.6) & 63.750 & 0.251 \\
\hline $2.50-3.23$ & $3(10.0)$ & $17(28.3)$ & $20(22.3)$ & & \\
\hline $3.25-3.98$ & $0(0.0)$ & $1(1.7)$ & $1(1.1)$ & & \\
\hline$\geq 4.00$ & $0(0.0)$ & $0(0.0)$ & $0(0.0)$ & & \\
\hline \multicolumn{6}{|l|}{$\mathrm{TG}(\mathrm{mmol} / \mathrm{L})$} \\
\hline$<3.75$ & $27(90.0)$ & $52(86.0)$ & 79 (87.5) & 60.154 & 0.263 \\
\hline $3.75-4.98$ & $3(10.0)$ & $8(14.0)$ & $11(12.5)$ & & \\
\hline$\geq 5.00$ & $0(0.0)$ & $0(0.0)$ & $0(0)$ & & \\
\hline \multicolumn{6}{|l|}{$\mathrm{HDL}-\mathrm{C}(\mathrm{mmol} / \mathrm{L})$} \\
\hline$\leq 0.98$ & $9(30.0)$ & $18(30)$ & $27(30.0)$ & 40.886 & 0.867 \\
\hline $1.00-1.48$ & $12(40.0)$ & $25(41.7)$ & $37(41.2)$ & & \\
\hline$\geq 1.50$ & $9(30.0)$ & $17(28.3)$ & $26(28.8)$ & & \\
\hline Incomplete result & $3(9.1)$ & $11(15.5)$ & $14(13.5)$ & & \\
\hline
\end{tabular}

[36,37]. Combined systolic and diastolic hypertension as well as pure diastolic hypertension was more prevalent in males than females but the difference was not significant. The sex difference was similar to previous findings $[7,36,37]$. The prevalence of ISH was similar in both sexes.

The prevalence of obesity was $14.4 \%$, with a higher rate in females $(18.3 \%)$ than in males $(6.0 \%)$. This may be related to the higher level of physical activity of men arising from their farming activities, while females engage in more sedentary activities such as trading. This is in accord with several previous studies [21,22,35]. Under-nutrition was also observed with a prevalence of $5.8 \%$, and was commoner in males $(6.1 \%)$ than in females $(5.6 \%)$, though this was not a significant difference. This under-nutrition coexisting with obesity demonstrates a double burden in this community.

Abdominal obesity, as measured by waist circumference and perhaps a more sensitive measure of obesity in African populations [38,39], was observed in $38.46 \%$ of the participants, with a significantly higher rate in females (52.11\%) compared with males (9.09\%). This can be explained as a result of high caloric expenditure physical activities (farming) that predominate in males in this study compared with low caloric expenditure sedentary activities (trading) that predominate in females. This finding is similar to reports by Andre et al. [24] and Adegoke et al [40]. The smoking frequency among the participants was very low $(2.9 \%)$, probably because of the religious nature of the community as well as poverty. Only a few of those who consumed alcohol (30.8\%) were at high risk (1\%), unlike the finding by Joel et al. in an African population [23], and this was also probably related to religion and poverty.

The low prevalence of diabetes observed in this study is similar to previous studies [35,36]. This may result from the absence of an affluent lifestyle and fewer problems with obesity when compared with more developed societies. The female preponderance was in tandem with other indicators of insulin resistance in this study, such as abdominal obesity (a well-known risk factor for metabolic syndrome and type II diabetes) [41,42], generalised obesity, and physical inactivity.

The high overall prevalence of overweight (29.8\%)/ generalised obesity (14.4\%), truncal obesity (38.5\%) and physical inactivity (29.8\%) could partly be explained by a lack of access to leisure activity (recreation) in this community as well as a substantial proportion (26.9\%) of the population in sedentary work (trading).

The lipid profile in this population was predominantly within the desired range, similar to previous reports $[43,44]$, with almost no abnormalities in TC, LDL-C, and TG. The occupation of these individuals who are mainly farmers with high caloric expenditure may explain these results. Despite these observations, 30\% of the participants had low HDL-C, which may not be unconnected with lack of dynamic (aerobic) exercise in this population as this probably is the most important among lifestyle interventions for raising HDL-C $[45,46]$, and the similarities between males and females may be 
explained by the high number of postmenopausal females in whom the influence of oestrogen would be attenuated [46].

In conclusion, except for hypertension, obesity, physical inactivity and low HDL-C, the low proportion of most of the traditional cardiovascular risk factors such as smoking, high-risk alcohol consumption, diabetes, and high levels of TC, LDL-C, and TG was impressive. However, it is important to further emphasize the health benefits of reducing risk factors in an educational programme in this kind of community. The high prevalence of hypertension in this community is of concern, with possible sequelae of stroke, cardiac arrest, and heart failure. Therefore, this report highlights an urgent need for preventive and control educational programmes in a community of this nature.

\section{Competing interests}

The authors declared that they have no competing interests.

\section{Authors' contributions}

OJO (corresponding author) designed the study, contributed to data collection and statistical analysis, wrote the protocol, and was involved in the first through to the final draft of the manuscript. OOA contributed to data collection and literature searches. $\mathrm{OOO}$ and $\mathrm{BOA}$ contributed to writing the manuscript. All authors have read and approved the final manuscript.

\section{Acknowledgments}

We thank Drs OE Olalekan, OO Oguntoye, P Olowoyo, AO Adeagbo, AO Esan, AO Adeoye, members of staff of the Comprehensive Health Centre, Aaye Ekiti, and community members of Aaye Ekiti. The blood glucose and lipid panel tests were sponsored by Pfizer Global Pharmaceuticals.

\section{Author details}

${ }^{1}$ Department of Internal Medicine, Cardiac Centre, Federal Medical Centre, Ido-Ekiti, Ekiti State, Nigeria. ${ }^{2}$ Department of Internal Medicine, Federal Medical Centre, Ido-Ekiti, Ekiti State, Nigeria. ${ }^{3}$ Division of Cardiovascular Medicine, College of Medicine, University of Ibadan, Ibadan, Nigeria. ${ }^{4}$ Department of Community Medicine, Federal Medical Centre, Ido-Ekiti, Ekiti State, Nigeria.

Received: 19 February 2013 Accepted: 10 October 2013 Published: 20 October 2013

\section{References}

1. Murray CJL, Lopez AD: Mortality by cause for eight regions of the world: Global Burden of Disease study. Lancet 1997, 349:1269-1276.

2. Murray CJL, Lopez AD: The global burden disease. A comprehensive assessment of mortality and disability from disease, injuries, and risk factors in 1990 and projected to 2020. http://www.worldbank.org/transport/roads/ saf_docs/gbd.pdf.

3. Thomas AG, Michael JG: Harrison's Principles of internal medicine. In Global Burden of cardiovascular Disease. Volume 1. 9th edition. Edited by Robert OB, Douglas LM, Douglas PZ, Peter L. Philadelphia: Elsevier Saunders; 2012:1-20.

4. Hennekens $\mathrm{CH}$ : Increasing burden of cardiovascular disease: current knowledge and future directions for research on risk factors. Circulation 1998, 97:1095-1102.

5. Bank TW: World Development indicators. http://data.worldbank.org/datacatalog/world-development-indicators.

6. Mancia G, De Backer G, Dominiczak A, Cifkova R, Fagard R, Germano G, Grassi G, Heagerty AM, Kjeldsen SE, Laurent S, et al: 2007 ESH-ESC Practice Guidelines for the Management of Arterial Hypertension: ESH-ESC Task Force on the Management of Arterial Hypertension. J Hypertens 2007, 25(9):1751-1762
7. Chobanian AV, Bakris GL, Black HR, Cushman WC, Green LA, Izzo JL Jr, Jones DW, Materson BJ, Oparil S, Wright JT Jr, et al: The Seventh Report of the Joint National Committee on prevention, detection, evaluation and treatment of high blood pressure: the JNC 7 Report. JAMA 2003, 289(19):2560-2572

8. Williams B, Poulter NR, Brown MJ, Davis M, Mclnnes GT, Potter JF, Sever PS, McG Thom S: British Hypertension Society. Guidelines for management of hypertension: report of the fourth working party of the British Hypertension Society, 2004-BHS IV. J Hum Hypertens 2004, 18:139-185.

9. Whitworth JA: World Health Organisation- International Society of Hypertension writing group. World Health Organisation- International Society of Hypertension Statement on management of hypertension. J Hum Hypertens 2003, 21:1983-1992.

10. American Diabetes Association: Diagnosis and classification of diabetes mellitus. Diabetes care 2010, 33(supply 1):562.

11. Reardon T, Berdegue J, Escoban G: Rural Non-farm Employment and Incomes in Latin America. World Dev 2001, 29:395-409.

12. Expert Panel on Detention, Evaluation, and Treatment of High Blood Cholesterol in Adults: National Cholesterol Education Programme: Report of the Expert Panel on Detection, Evaluation, and Treatment of High Blood Cholesterol (Adult Treatment Panel III). JAMA 2001, 285:2486-2497.

13. World Health Organization: Physical Status: The Use And Interpretation of Anthropometry - Report of a WHO Expert Committee. Geneva: WHO Technical Report Series; 1995:854

14. World Health Organization: Obesity: Preventing and managing the global epidemic- Report of a WHO consultation. WHO Technical Report Series; 2000:894.

15. NHS Lothian Health Promotion Service: Current daily sensible drinking guidelines for adults. www.nhslothian.scot.nhs.uk.

16. Elley W, Kerse NM, Swinburn B, Aroll B: Measuring physical activity in primary health care research; Validity and reliability of two questionnaires. N Z fam pract 2003, 30:171-180.

17. National Centre for Health Statistics: National Health and Nutrition Examination Survey: body Composition Procedures Manual. http://www.cdc. gov/nchs/data/nhanes/bc.pdf.2008.

18. Manson C, Katzmarsyk PT: Variability in waist circumference measurements according to anatomic measurement site. Obesity (Silver Spring) 2009, 17:1789-1795.

19. Reza GS, Hadi A, Babak D: Socieconomic status and class perception. IJLS 2007, 3:183-200

20. Brown DF: "Social class and status". Mey, Jacob. Coincise Encyclopedia of pragmatics. Elsevier; 2009.

21. Okesina AB, Oparinde DP, Akindoyin KA, Erasmus RT: Prevalence of some risk factors of coronary heart disease, in a rural Nigerian population. East Afr Med J 1999, 76:212-216.

22. Adedoyin RA, Mbada CE, Balogun MO, Adebayo RA, Martins T, Ismail IS: Obesity prevalence in adult residents of lle-lfe, Nigeria. Nig Q J Hosp Med 2009, 19:63-68.

23. Joel N, Robert C, Sarah S, Seye A, Sonia ES: Risk factors for noncommunicable diseases among older adults in rural Africa. Trop Med Int Hith 2011, 16:640-646.

24. Andre CM, Ana NL: Assessment of cardiovascular risk factors in a rural community in the Brazilia State of Bahia. Arg, Bras Cardiol 2003, 81:297-302.

25. Sobngwi E, Mbanya JCN, Unwin NC, Kengne AP, Fezeu L, Minkoulou EM, Aspray TJ, Alberti KGMM: "Physical activity and its relationship with obesity, hypertension and diabetes in urban and rural Cameroon. Inter J of Obesity 2002, 26(7):1009-1016.

26. Christensen DL, Eis J, Hansen AW, Larsson MW, Nwaniki DL, Kilonzo B, Tetens I, Bolt MK, Kaduka L, Borch-Johnsen K, Friis H: "Obesity and regional fat distribution in Kenyan populations: impact of ethnicity and urbanization. Ann of Hum Biology 2008, 35(2):232-249.

27. Njelekela M, Negishi H, Nara Y, Tomohiro M, Kaga S, Noguchi T, Kanda T, Yamori M, Mashalla Y, Liu LJ, Mtabaji J, Ikeda K, Yamori Y: Cardiovascular risk factors in Tanzania: a revisit. Acta Trop 2001, 79(3):231-239.

28. Ineid H, Fonarow GC, Cannon CP: Sex differences in medical care and early death after acute myocardial infarction. Circulation 2008, 118:2803.

29. Lyoyd-Jones D, Adams R, Carnethon: Heart disease and stroke statistics-2009 update: A report from the American Heart Association Statistics Committee and stroke statistics Subcommittee. Circulation 2009, 119:21. 
30. Yusuf S, Reddy S, Onnpuu S, Anand S: Global burden of cardiovascular diseases: part I: general considerations, the epidemiologic transition, risk factors, and impact of urbanization. Circulation 2001, 104:2746.

31. Pobee JO: Community-based high blood pressure programs in subSaharan Africa. Ethn Dis 1993, 3:S38-S45.

32. Adedoyin RA, Mbada CE, Balogun MO, Martins T, Adebayo RA, Akintomide A, Akinwusi PO: Prevalence and pattern of hypertension in a semi-urban community in Nigeria. Eur J Cardiovasc Prev Rehab 2008, 15:683-687.

33. Addo J, Amoah AGB, Kwadwo KA: "The changing patterns of hypertension in Ghana: a study of four rural communities in the Ga District. Ethn Dis 2006, 16(4):894-899.

34. Maas AHEM, Franke HR: Women's health in menopause with a focus on hypertension. Neth Heart J 2009, 17(2):68-72.

35. Onwubere BJC, Ejim EC, Okafor Cl, Emehel A, Mbah AU, Onyia U, Mendis S: Pattern of blood presure indices among the residents of a rural community in the South East Nigeria. Int J Hypertens 2011, 2011:1-6.

36. Franlins S, Gustin WT, Wong M: Haemodynamic Patterns of age-related changes in blood pressure. The Framingham Heart Study. Circulation 1997, 96:308-412.

37. Haijar I, Kotchen T: Trends in prevalence, awareness, treatment and control of Hypertension in the United States, 1988-2000. JAMA 2003, 290:199-205.

38. Steyn K, Silwa K, Hawken S: Risk factors associated with myocardia infarction in Africa: the INTERHEART Africa study. Circulation 2005, 112:3554-3561.

39. Maher D, Waswa L, Baisley K, Karabarinde A, Unwin N, Grosskurth $\mathrm{H}$ : Distribution of hyperglycaemia and related cardiovascular disease risk factors in low-income countries: a cross-sectional population-based survey in rural Uganda. Int J Epidemiol 2011, 40(1):160-171.

40. Adegoke OA, Adedoyin RA, Balogun MO, Adebayo RA, Bisiriyu LA, Salawu AA: Prevalence of metabolic syndrome in a rural community in Nigeria. Metab Syndr Relat Disord 2010, 8(1):59-62.

41. Cappuccio FP, Micah FB, Emmett L, Kerry SM, Antwis S, Martin-Peprah R, Phillips RO, Plange-Rhule J, Eastwood JB: Prevalence, Detection, Management, and control of Hypertension in Ashanti, West Africa. Hypertens 2004, 43:1017-1022.

42. Reaven GM: Role of insulin resistance in human disease. Diabetes 1988 , 37:1595-1607.

43. Oladapo OO, Salako L, Sodiq O, Shoyinka K, Adedapo K, Falase AO: A prevalence of cardiometabolic risk factors among a rural Yoruba South-Western Nigeria Population: a population-based survey. Cardiovasc J Afr 2010, 21:26-31.

44. Ezenwaka CE, Akanji AO, Akanji BO, Unwin NC, Adejuwon CA: The prevalence of insulin resistance and other cardiovascular disease risk factors in healthy elderly Southwestern Nigerians. Atherosclerosis 1997, 128:201-211.

45. Williams PT: Relationship of distance run per week to coronary heart disease risk factors in 8283 male runners. The National runners' Health study. Arch Intern Med 1997, 157:191-198.

46. Durstine JL, GrandJean PW, Daris PG, Ferguson MA, Alderson NL, Debose KD: Blood lipid and lipoprotein adaptations to exercise: a quantitative analysis. Sports Med 2001, 31:1033-1062.

doi:10.1186/1471-2261-13-89

Cite this article as: Ogunmola et al.: Prevalence of cardiovascular risk factors among adults without obvious cardiovascular disease in a rural community in Ekiti State, Southwest Nigeria. BMC Cardiovascular Disorders 2013 13:89

\section{Submit your next manuscript to BioMed Central and take full advantage of:}

- Convenient online submission

- Thorough peer review

- No space constraints or color figure charges

- Immediate publication on acceptance

- Inclusion in PubMed, CAS, Scopus and Google Scholar

- Research which is freely available for redistribution 